Anales de Literatura Hispanoamericana

ISSN-e: 1988-2351

\title{
Martí y Vallejo: la angustia que salvará a la humanidad
}

Víctor Manuel Ramos ${ }^{1}$

Resumen. En este artículo se reflexiona sobre una serie de texto de José Martí con una serie de imágenes poéticas que anuncian la voz de César Vallejo.

Palabras clave: José Martí; César Vallejo.

\section{[en] Martí and Vallejo: the Anguish that will Save Humanitys}

Abstract. This article reflects on a series of texts by José Martí with a series of poetic images that announce the voice of César Vallejo.

Keywords: José Martí; César Vallejo.

Cómo citar: Ramos, V.M. (2020) Martí y Vallejo: la angustia que salvará a la humanidad, en Anales de Literatua Hispanoamericana 49, 133-137.

En 2003, cuando actuaba como Director del Fondo Editorial de la Universidad Pedagógica Nacional Francisco Morazán, para celebrar el ciento cincuenta aniversario del nacimiento de José Martí ${ }^{2}$, edité un precioso libro del patriota y poeta cubano titulado Tallar en nubes. La obra es una recopilación de textos breves, agradables a todos los sentidos, como apunta el antólogo y prologuista, Orlando González Esteva. No fue fácil sacar adelante la edición porque, a pesar del respaldo que me daba el Rector ${ }^{3}$, había unos personajes pérfidos que obstaculizaban mi trabajo. Los textos de este libro, colocados cada uno en una página para que, como quiso el antólogo, brillaran por sí mismos, fueron extraídos, como diamantes de una mina, de los "Cuadernos de apuntes», recopilados en los tomos 21 y 22 de la Obras Completas de José Martí, que corresponden a las publicadas por la Editorial Ciencias Sociales, de La Habana, en 1975. En esa editorial trabajaba mi inolvidable amigo, amante de Honduras, el filólogo de Gazapos, Fernando Car Parrúas, como lector y corrector. "Los cuadernos de apuntes... corresponden a la papelería del Maestro a los que se refirió, en su carta testamento literario a su discípulo predilecto Gonzalo de Quesada y Aróstegui, y se componen, en su mayor parte, de hojas de papel, cosidas con hilo".

Iniciar la lectura de Tallar en nubes es para no dejar el libro. Está lleno de sutilezas y de insospechadas sorpresas, escritas con una brevedad y sencillez de asombro, de tal modo que, aunque los mexicanos consideran a Julio Torri, con sus Ensayos y poemas (1919) y a Carlos Días Dufoo, con sus Epigramas (1927) como los fundadores y precursores del relato breve o minicuento, después de la lectura de este libro de Martí, no cabe duda que la gloria de iniciador de la minificción, en la América Nuestra, corresponde al poeta y patriota cubano.

Para mí, lector asiduo y amante de la obra de César Vallejo, desde mis años de juventud, la sorpresa extraordinaria llegó cuando leí la última página (209) del volumen:

\footnotetext{
1 Miembro Miembro de número de la Academia Hondureña de la Lengua. Tegucigalpa. Honduras.

E-mail: vmramos238@gmail.com

${ }^{2}$ Enero 28, viernes. José Martí nace en La Habana, en la calle de Paula N ${ }^{\circ}$. 41, hoy Leonor Pérez $N^{\circ}$. 314, en donde actualmente se encuentra instalado el Museo losé Martí, el primogénito hijo de Mariano Martí y Navarro, sargento primero del Real Cuerpo de Artillería, natural de Valencia, y de Leonor Pérez y Cabrera, natural de Santa Cruz de Tenerife.

${ }^{3}$ Msc. Ramón Ulises Salgado.
} 
Oyó: se levantó dolorosamente: compuso los huesos rotos de su cráneo, y siguió andando. (Martí: 209)

Inmediatamente el ruido de esas palabras despertó mis pensamientos ${ }^{4}$ y me llevó a César Vallejo, a su renombrado y conocido poema Masa:
Al fin de la batalla, y muerto el combatiente, vino hacia él un hombre
y le dijo: «iNo mueras, te amo tanto!»
Pero el cadáver ¡ay! siguió muriendo.

Se le acercaron dos y repitiéronle:

« ¡No nos dejes! ¡Valor! ¡Vuelve a la vida!»

Pero el cadáver ¡ay! siguió muriendo.

Acudieron a él veinte, cien, mil, quinientos mil, clamando «iTanto amor y no poder nada contra la muerte!»

Pero el cadáver ¡ay! siguió muriendo.

Le rodearon millones de individuos, con un ruego común: «iQuédate hermano!»

Pero el cadáver ¡ay! siguió muriendo.

Entonces todos los hombres de la tierra

le rodearon; les vio el cadáver triste, emocionado;

incorporóse lentamente,

abrazó al primer hombre; echóse a andar...

(Darío y Vallejo: 228)

Entonces me dije, con palabras de Martí: "Quien bien vela todo se le revela” (Martí: 42). Y pensé: Aquí está el origen del poema Masa de César Vallejo. Y si no es así, indudablemente, entre hombres que tenían una preocupación común, la libertad de sus pueblos, bien pudo haber una trasmutación de ideas a lo largo del tiempo entre los dos gigantes de las letras americanas. Pero, estudiando con mayor serenidad el asunto, mis pesquisas me llevaron a saber que los Cuadernos de notas no fueron publicados sino hasta 1975, razón por la cual el poeta peruano no pudo tener a su alcance este texto de Martí y, por tanto, no existe conexión alguna entre el texto de Martí y las lecturas de Vallejo. Pero pudo ser que Vallejo:

Llama a las puertas de lo infinito. Decidido a abrirlas. Se pone su armadura de hombre y con el puño levantado, como quien despierta a un perezoso, escalando sin miedo las nubes, y sin cuidar de los creyentes que le ladran y de los timoratos que le abandonan, llama a las puertas de lo infinito, decidido a abrirlas. (Martí: 24)

Y, de esa manera logra la comunicación con el excelso poeta cubano y de América.

Pero, si no es como dije arriba, cómo es que Vallejo logra abrir las puertas del pensamiento martiano, las de la angustia común, las de los anhelos comunes, y logra una comunicación perfecta, aunque Martí había muerto en Dos Ríos, en Cuba, enfrentado a las tropas colonialistas españolas. Muere, Martí, y no se corre, en el combate sabiendo que la muerte le esperaba, como Vallejo anuncia la suya en un poema sombrío:

Me moriré en París con aguacero,

Un día del cual tengo ya el recuerdo.

Me moriré en París -y no me corro-, 
Tal vez un jueves, como es hoy, de otoño.

(Darío y Vallejo: 191)

Una misma angustia existencial corroía a los dos poetas, casi la misma de Bolívar por su Gran Colombia destrozada antes de morir: a Martí le atormentaba la libertad de Cuba y la Unidad de la América Nuestra frente al imperialismo, a Vallejo, la libertad de su Perú indiano, la supervivencia de la República Española y, como marxista firme, también, la Unidad de América frente al imperialismo. Les unía el odio revolucionario hacia la injusticia y el atropello: "Yo sé muchas cosas, y entre otras, sé lo que debe sentir una margarita cuando se la come un caballo!", escribió Martí. Y Vallejo, en su poema Los heraldos negros, nos transmite un dolor infinito: "Hay golpes en la vida, tan fuertes... Yo no sé!" (Darío y Vallejo: 141).

Podría decirse que ambos, frente a ese ideal libertario que albergaban, eran, como decía Romain Rolland de Beethoven, "el dolor hecho hombre". A tal grado que Martí murió de Cuba ${ }^{5}$ y Vallejo "murió de España" (Adoum: 19). De Cuba pisoteada por la bota colonial y amenazada por la garra imperialista y de España, descuartizada por Franco y reducida a un guiñapo con sus mejores hombres asesinados o en el exilio. Martí recibió tres balazos de parte de la tropa colonialista española, Vallejo recibió todas las balas de todos los Pedros Rojas que mataron y por los que lloró España, incluidas las que asesinaron a García Lorca.

Así escribe el Gran Rubén Darío en su trabajo José Martí, incluido en Los Raros:

desalentado, él tan grande y tan fuerte. Dios mío! Desalentado en sus ensueños de arte, remachó con triples clavos dentro de su cráneo la imagen de su estrella solitaria, y dando tiempo, se puso a forjar armas para la guerra a golpe de palabra, y a fuego de idea. Paciencia, la tenía; esperaba y veía como en una Fatamorgana, su soñada Cuba Libre. (Darío 2015)

\section{Cintio Vitier recordó a Vallejo:}

Cuando hice el hallazgo, en un día inolvidable, del quemadísimo César Vallejo, comprendí, como nunca, escanciado por él hasta el hueso natal de la vida, ese sentido de oscuro, trágico salmista que al poeta auténtico, no obstante toda posible apariencia, lo empuja en lo más hondo. (Vitier: 470)

Vallejo fortaleció su marxismo en Moscú, capital de la Unión de Repúblicas Socialistas y fue el marxismo la ideología que le formó su espíritu libertario y humanista. Aunque, desde Perú, a través de la Revista Amauta, que dirigió José Carlos Mariátegui, se había encaminado por esas rutas:

Hoy, y más que nunca quizás, siento gravitar sobre mí, una hasta ahora desconocida obligación sacratísima, de hombre y de artista: la de ser libre! Si no he de ser hoy libre, no lo seré jamás. Siento que gana el arco de mi frente su más imperativa fuerza de heroicidad. Me doy en la forma más libre y que puedo, y esta es mi mayor cosecha artística. (Paredes Rafael: 8)

José Martí adquirió su ideal libertario en la Cuba misma, en las cárceles de España y luego en su Isla y en su periplo por América. Podría decir que también estuvo en la Unión Soviética porque Fidel, quien se encargó de realizar, como pensamiento y obra, el ideal martiano, se hermanó con la URSS, como único camino para asegurar la pervivencia de la revolución cubana.

El texto de Martí emparentado con el poema Masa de Vallejo es, de alguna manera, el extremo inicial del hilo que conducirá a Vallejo. Martí habla de un individuo que ama la vida y que se incorpora como el

\footnotetext{
${ }^{5}$ José Miró Argenter que afirma: "Buscó él mismo la muerte (no cabe otra deducción dentro de la lógica humana), solicitado por la grandiosidad de su destino que le ofrecía aquella ocasión de alcanzar la inmortalidad, la primera que le brindaba la fortuna, creyendo que el acoso no iba a prestarle ninguna otra más propicia ni más memorable"; diversos historiadores han refutado esta tesis a lo largo del tiempo. El historiador Leonardo Griñán Peralta escribió: “... no hay ninguna razón valedera para demostrar que su muerte en Dos Ríos tuvo caracteres de suicidio. No hay gran político que, conscientemente, quiera morir al acabar de pronunciar solemnemente estas palabras: 'yo evoqué la guerra; mi responsabilidad comienza con ella en vez de acabar [...]'. En aquellos momentos morir era fracasar y no hay líder político a quien no horrorice cuanto pueda posibilitar el fracaso del ideal al que ha consagrado su vida. El éxito de la causa que defiende le importa más que la gloria de su muerte bella. Y si en aquel momento pudo parecerle bella la muerte, es imposible que le halla parecido oportuna...”. Según Jorge Mañach el Apóstol fue un hombre signado por la incomprensión y que, sin embargo, supo sobreponerse a estas adversidades, por lo tanto, su accionar no se corresponde con el suicidio. (Hospital Provincial Universitario “Arnaldo Milián Castro”, en Valoración histórica de la muerte de José Martí. MSc. Dra. Marta de las Mercedes Rojas Pérez, Lázara de las Mercedes Martínez Rojas y Lirilsy Fernández Gómez).
} 
hombre o la mujer de Masa. El sujeto martiano primero Oye a alguien que escucha sus lamentos porque va muriendo. Inexorablemente percibe el llamado y eso le hace volver a la vida. La respuesta a ese llamado humanitario: "Oyó: se levantó dolorosamente: compuso los huesos rotos de su cráneo, y siguió andando". Yo digo que es el extremo del cabo del hilo conector entre los dos poetas porque el humano martiano responde al primer llamado, actitud que está inmersa en un profundo amor al prójimo que hay en Martí pero que es individualista y que no llega al otro extremo de hilo en donde Vallejo, ya nutrido en las doctrinas de comunismo asume que el humano que muere no responde al llamado de un individuo, ni de muchos, sino de la humanidad misma, para incorporarse y echarse a andar. Se trata de una solidaridad más cálida, más humana, más imbuida de un amor humano colectivo. Solidaridad de esta naturaleza que si encontramos en el pensamiento martiano de Fidel y de sus extensiones en El Che, Omar Torrijos, Hugo Chávez y muchísimos más.

Martí podría ser ese mismo hombre que compuso los huesos rotos de su cráneo y siguió andando, no por el mundo de la vida biológica, sino por el mundo que le catapultó a la eternidad pues, ¿por qué no pensar que a quién oyó fue a la Cuba misma? Y a pesar de que las balas descompusieran los huesos rotos de su cráneo, Cuba que le vio yacente, tumbado, sangrante, herido de muerte, le habló. Él oyó el llamado y se echó a andar por siempre.

Vallejo también vio a un humano tirado en el suelo:

Lo han matado, obligándole a morir

A Pedro, a Rojas, al obrero, a aquel

Que nació muy niñín, mirando el cielo

Y que luego creció, se puso rojo

Y luchó con sus células, sus nos, sus todavías, sus hambres, sus pedazos.

Su cadáver estaba lleno de mundo.

(Vallejo, cit. Valcárcel: 14)

Martí y Vallejo habían nacidos para comprender, completamente, al hombre, a la humanidad entera. Razón misma, por la cual, ambos lloran ante las desventuras de la humanidad. Porque Martí "Se alimentaba de grandes pensamientos" y Vallejo "Se alimentaba de grandes pensamientos" (Martín: 47).

"Oigo en todas partes sollozos -porque estoy lleno de ellos" (Martín: 69), clama Martí. Y Vallejo lanza un grito desgarrador: "carne de llanto, fruto de gemido" (Darío y Vallejo: 204).

José Ángel Valente, al referirse al poema Masa, escribió:

Pocas veces el sentimiento de solidaridad, que había de caracterizar de un modo colectivo a la poesía posterior, ha encontrado manifestación más intensa que en el poema "Masa" de España aparta de mí este cáliz. (Valente: 16)

Esto es cierto porque Vallejo, en este poema Masa, reúne todo el amor del mundo necesario para que el hombre, la mujer, todos los hombres, todas las mujeres, la humanidad se levanten y echen a andar.

Martí y Vallejo han compartido un tema fundamental, un tema de vida; un tema esencial y necesario en este mundo dominado por camarillas más interesadas en las ganancias monetarias que en el bienestar del hombre común, el hombre del pueblo, el que acude a diario, sin el estímulo que debería de recibir si viviera en una sociedad justa, a la usina, a la parcela agrícola, al aula o la establecimiento sanitario. Hay actualmente en el mundo poblaciones enteras que no comen y niños que mueren de hambre. Pero además, hombres, mujeres y niños que mueren como víctimas de guerras que imponen intereses extraños a los pueblos a tal grado que la ONU ha dejado de ser el baluarte de la paz y de la seguridad del mundo y de la humanidad. Un gobierno ahora ha asumido la función de sancionar a los pueblos.

Hagamos, todos a una, con Martí y Vallejo, que superemos la angustia por la injusticia que persigue al mundo.

\section{Referencias bibliográficas}

Adoum, Jorge Enrique (1969). "César Vallejo”, Publicación de Arte y Letras del Departamento Editorial, año 3, n 2627, setiembre y octubre de 1960, Universidad de Honduras.

Darío, Rubén. (2015). Los raros. Ed., int. y notas Günther Schmigalle. Berlín: Edition tranvía/Verlag Walter Frei. 
Darío, Rubén y César Vallejo (1999). Heraldos del Nuevo Mundo. Intr., sel. y notas de Álvaro Urtecho y Ricardo González Vigil. Managua: Banco Central de Nicaragua.

Martí, José (2003). Tallar en nubes. Selección y prólogo de Orlando González Esteva. Edición conmemorativa del 150 aniversario del nacimiento de José Martí. Tegucigalpa: Fondo Editorial/Universidad Pedagógica Nacional Francisco Morazán.

Paredes Rafael, Paz (1969), “Actualidad americana de César Vallejo”, Publicación de Arte y Letras del Departamento Editorial, año 3, n 25, agosto de 1960, Universidad de Honduras.

Valcárcel, Gustavo (1960), “Algunos apuntes sobre la poesía de César Vallejo”. Publicación de Arte y Letras del Departamento Editorial, año 3, n 26-27, setiembre y octubre de 1960, Universidad de Honduras.

Valente, José Ángel (1960), “César Vallejo, desde esta orilla", Publicación de Arte y Letras del Departamento Editorial, año 3, n⿳ 26-27, setiembre y octubre de 1960, Universidad de Honduras.

Vitier, Cintio (1999), "Vallejo, un hombre que reclama nuestro amor", en Rubén Darío y César Vallejo. Heraldos del Nuevo Mundo. Managua: Banco Central de Nicaragua. 